\title{
Residual protection on a wharf structure following application of impressed current cathodic protection
}

\author{
Shamir Bhuiyan, David Law* and Peter Nicholls \\ School of Engineering, RMIT University, Melbourne, VIC, 3001, Australia
}

\begin{abstract}
Recent studies have suggested that residual protection is afforded to structures following the application of impressed current cathodic protection (ICCP), in some cases for significant periods of time, while others for periods of only a few days. This study reported the findings of the de-activation of a 20 year old ICCP system installed on a 50 year old structure. The ICCP was deactivated for 84 days and the steel potentials at locations on the front pile cap and front wall were monitored via the installed reference electrodes. An adjacent water anode system was also deactivated for 48 hours during the initial de-activation period to observe the impact on the steel potentials. The results showed that out of 42 reference electrodes, 17 achieved a $100 \mathrm{mv}$ decay within 24 hours and 10 had more positive instant off potentials than $-150 \mathrm{mV}$. Furthermore, all displayed a positive shift in potential following deactivation of the ICCP system for a period of time, indicative of residual protection, with 22 displaying this positive shift for the whole 94 days of the trial.
\end{abstract}

\section{Introduction}

Reinforced concrete is one of the most widely employed construction materials, being utilized for structures including bridges, dams, high rise blocks, power plants, docks etc. The reinforcing steel is normally passive in concrete due to the high $\mathrm{pH}$ environment provided by the Portlandite, sodium and potassium hydroxides and C-S$\mathrm{H}$ gel formed by the hydration of the cement [1]. This leads to the formation of iron oxides and hydroxides on the steel surface which prevent the oxidation of the reinforcing steel, and in doing so create a passive oxide layer on the steel which prevents corrosion [2]. However, when chlorides enter the concrete and reach a sufficient concentration at the rebar, known as the critical chloride threshold or $\mathrm{C}_{\text {crit }}$, they can disrupt this passive layer and initiate corrosion of the steel $[3,4]$. Once corrosion has been initiated the steel will start to corrode which will eventually lead to cracking and spalling of the concrete and significant loss of section in the reinforcing bars, until the structural integrity of the structure is compromised. Chloride induced corrosion of reinforced concrete structures is one of the major causes of deterioration worldwide, with repair and maintenance costs of billions of dollars required to maintain the operation of these critical parts of the infrastructure.

One of the most effective methods of providing protection for reinforced concrete structures is Impressed Current Cathodic Protection (ICCP). Other methodologies can be employed such as; patch repair, realkalisation, sacrificial cathodic protection, hybrid cathodic protection and chloride extraction [5]. However, ICCP remains the primary methodology for corrosion protection, particularly in aggressive marine environments. ICCP protects the steel by applying a direct current to polarise the steel to more negative values, re-establishing passivity in the steel. This is achieved by a kinetic reduction in the over potential of actively corroding steel resulting in a decrease in the corrosion current density and consequently of the dissolution of the steel [6-8]. In addition there are a number of secondary mechanisms which also contribute to the long term protection of the steel [9]:

- The production of hydroxyl ions

- The breakdown of oxygen gas

- The repulsion of aggressive anions

Recent studies have reported that residual protection has been observed on structures where ICCP systems have been de-activated for periods of time, or decommissioned [10, 11]. A study of ten structures in the United Kingdom showed that the steel remained passive for three years after the ICCP was decommissioned [12, 13]. Similar findings have also been reported on two marine structures in Australia [14]. However, residual protection has not been observed in all reinforced concrete structures, with corrosion having been re-initiated within as little as three days [14]. The reasons for these variations in performance have been attributed to a number of factors relating to the operation of the ICCP system or the secondary effects. These include charge passed, charge density, duration of ICCP operation, system design, local environments including tidal cycles, moisture content, chloride concentrations and the chemistry of the electrolyte. Hence, significant

* Corresponding author: David.Law@ rmit.edu.au 
questions remain concerning the effects, causes and duration of residual protection from ICCP systems. This is of particular importance with many systems reaching the end of their design lifetimes. To further investigate these effects, this paper reports a study on a reinforced concrete wharf constructed in 1969 in southern Australia with an ICCP system that was installed in 1999.

\section{Methodology}

The study was conducted on Berth 6 at the Port of Portland in southern Victoria, Australia. Berth 6 was constructed in 1969 as part of the expansion of the Port, with the adjacent Berth 5 constructed in 1986. An ICCP system was installed on both Berth 6 and Berth 5 in 1999, due to deterioration caused by chloride induced corrosion of the reinforcing steel. As such the ICCP system has been in operation for almost 20 years.

The ICCP system consists of slotted anodes in the transverse pile headstock beams, internal anodes within the front curtain wall beam and soil anodes to protect the rear retaining wall. The slotted anodes are mixed metal oxide coated titanium ribbon located within narrow horizontal slots. The ribbon was embedded using a cementitious grout. The internal anodes were mixed metal oxide ceramic tubular anodes installed into horizontally drilled holes within the curtain wall beam. The anodes had a venting system to enable gases generated by the anodic reaction to diffuse into the centre of the porous anodes and to then vent to the atmosphere via a network of nylon tubes. The design was to allow the application of relatively high current densities to the anode in order to prevent deterioration of the backfill grout. The soil anodes were cast high silicon chromium iron anodes installed within vertically drilled holes behind the rear wall and backfilled with metallurgical coke breeze.

The slotted and internal anodes are powered by a transformer rectifier (TR) unit located in the electrical room towards the east end of the berth. The system is divided into eight operating zones with eight separate AC/DC controllers within the primary TR unit. The soil anodes are powered by zone 1 within the primary TR and a second TR unit to provide a maximum output of 20 Amps. A total of $52 \mathrm{Ag} / \mathrm{AgCl}$ permeant reference electrodes were embedded at representative locations throughout the reinforced concrete elements. Three in zone 1 to monitor the rear wall, 7 in Zone 2 to monitor the rear transverse beam and 7 in each of zones 3 to 8 . These were distributed across the six zones with 7 each in the tidal zone, the splash zone and the atmospheric zone of the front pile cap and the front wall. All cables are wired back to the primary TR unit. As built drawings of the system and the operating zones are shown in Figures $1 \& 2$. In addition, a water anode system protects the steel piles within Berth 5. This is expected to provide some current to the lower elements in Berth 6 (i.e. those located at or below mid-tide) of the ICCP system at high tide.

With the permission of the Port Authority, the ICCP system was decommissioned for a period of 84 days.
This time period was not prolonged any further as it was deemed sufficient for this study whilst minimising the impact on the structure. The water anode system was deactivated 2 hours following the de-activation of the ICCP system for a 48-hour period before re-activation, due to operational requirements. Once the ICCP system was disconnected, the steel potentials were monitored using a data-logger at 5 second intervals over the initial 5 minutes to record the instant-off data. Subsequently data points were recorded at 5 minute intervals in the initial 48-hour period when the water anodes were de-activated and then at 1-hour time intervals for the remainder of the de-activation period. Monitoring of the system commenced on the $30^{\text {th }}$ of November 2018 and the ICCP was re-activated on the 22nd of February 2019.

The reference electrodes in zone 1 , monitoring the rear wall and in zone 2 monitoring the transverse rear beam were not operational. As such, data was logged for the 42 reference electrodes in zones 3-6 for the front wall and front pile.

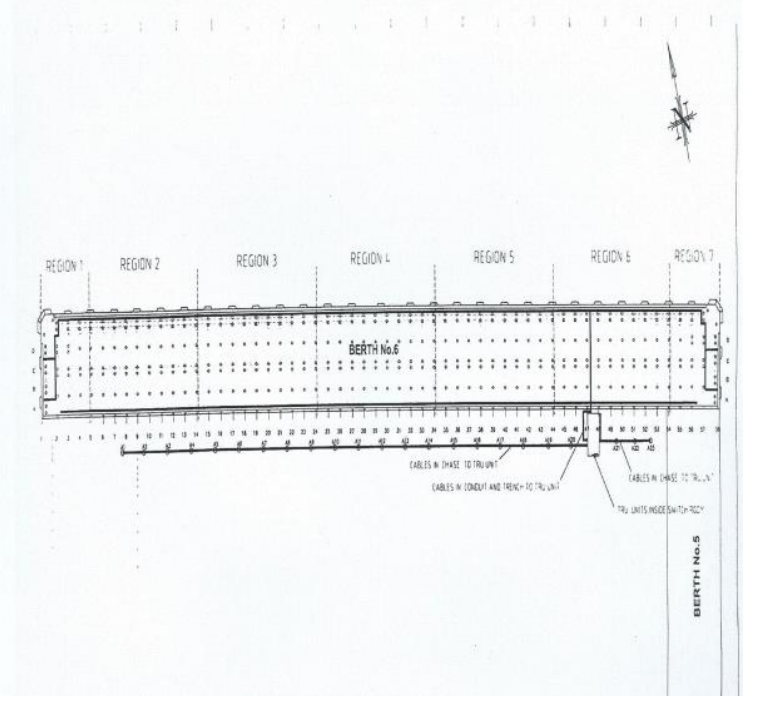

Fig. 1. As built drawing: Zonal Diagram Berth 6

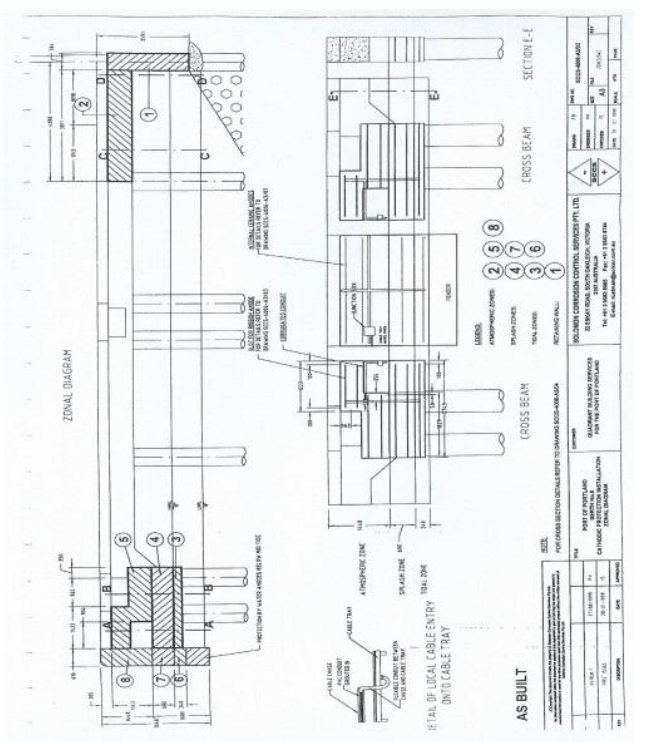

Fig. 2. As built drawing: Operating Zones Berth 6 


\section{RESULTS}

The system operates in accordance with AS 2832.5 [15], which considers the steel being protected from corrosion when one of the following criteria are met:

1. A potential decay over a maximum of 24 hours of at least $100 \mathrm{mV}$ from the instantaneous off potential. This is known as the potential decay criterion.

2. A potential decay over a maximum of 72 hours of at least $100 \mathrm{mV}$ from the instantaneous off potential subject to a continuing decay and the use of reference electrodes (not potential decay sensors or pseudo reference electrodes) for the measurement extended beyond 24 hours. This is known as the extended potential decay criterion.

3. An instantaneous off potential more negative than $720 \mathrm{mV}$ with respect to a silver/silver chloride reference electrode. This is known as the absolute potential criterion.

4. A fully depolarised potential, or a potential which is continuing to depolarise over 72 hours after the ICCP system has been switched off which is consistently less negative than $-150 \mathrm{mV}$ with respect to silver / silver chloride reference electrode. This is known as the absolute passive criterion.

It should be noted that a number of different standards used worldwide, in particular ISO 12696:2016 [16], upon which other standards (including AS 2832.5) are based, acknowledge that the above criteria are empirical in nature and allows for the use of corrosion risk assessment in order to assess the effectiveness of an ICCP system, should none of the criteria be met.

The on potential, instant off and 24-hour decay data are given in Table 1, together with the final potential before re-activation and the shift in this potential from the instant off potential. Decay curves from the tidal (zone 3), splash (zone 4) and atmospheric (zone 5) reference electrodes for front pile caps are given in Figure 3 and for the tidal (zone 6), splash (zone 7) and atmospheric (zone 8) reference electrodes for the front wall are given in Figure 4. These decay curves are typical for all reference electrodes in the front pile caps and the front wall across all zones.

The data for reference 25 showed a positive potential of $325 \mathrm{mV}$ which varied from +2000 to $-3000 \mathrm{mV}$ over the course of the 84 days. It was concluded that the data indicated that the reference electrode was not operating correctly, and this reference electrode was discounted from the analysis.

The decay curves clearly differentiate between the tidal, splash and atmospheric zones. The tidal zone potential trends are generally the most negative and the atmospheric zone always the most positive, with those in the splash zone being between the two other zones in most cases, though occasionally being more negative than the tidal zone. The tidal cycle is clearly evident on the reference electrodes located in the tidal and splash zones and is also evident on some of the reference electrodes in the atmospheric zone, Figure 5.

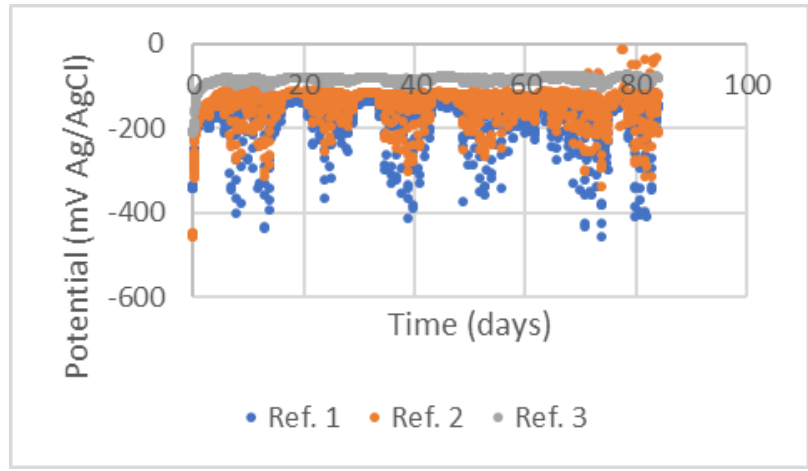

Fig. 3. Decay curves for reference electrode 1 (tidal, zone 3), reference electrode 2, (splash, zone 4) and reference electrode 3 (atmospheric, zone 5), Front Pile Caps

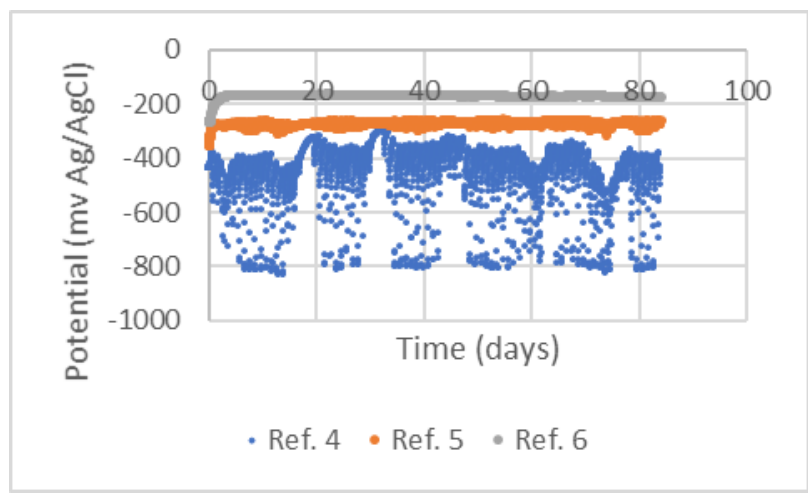

Fig. 4. Decay curves for reference electrode 4 (tidal, zone 6), reference electrode 5, (splash, zone 7) and reference electrode 6 (atmospheric, zone 8), Front Wall

The decrease in potential associated with the tidal cycles is generally of the order of $50 \mathrm{mV}$, though on occasion this does increase significantly, with potentials more negative than $-800 \mathrm{mV}$ being observed in the electrodes in the tidal zone. These falls in potential are consistent with those observed in previous studies and are attributed to the saturation of the concrete resulting in oxygen depletion resulting in the very negative potentials observed rather than the re-establishment of corrosion [17].

In addition to the normal tidal cycles there are a number of periods where the potentials remain relatively constant. E.g. days 17-20 and 30-33, Figure 3 and 4. These periods are associated with the mooring of ships in the berth. During these periods it is hypothesised that the berthed ships provide a protection against the tidal action of the waves and hence reduce the impact of the tides and the saturation of the concrete. 


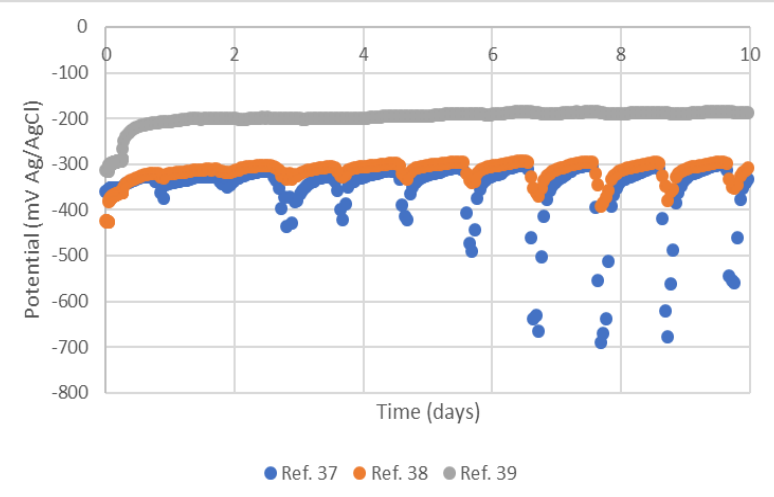

Fig. 5. Decay curves for reference electrode 37 (tidal, zone 3), reference electrode 38, (splash, zone 4) and reference electrode 39 (atmospheric, zone 5), Front Pile Caps, Day 0 to Day 10

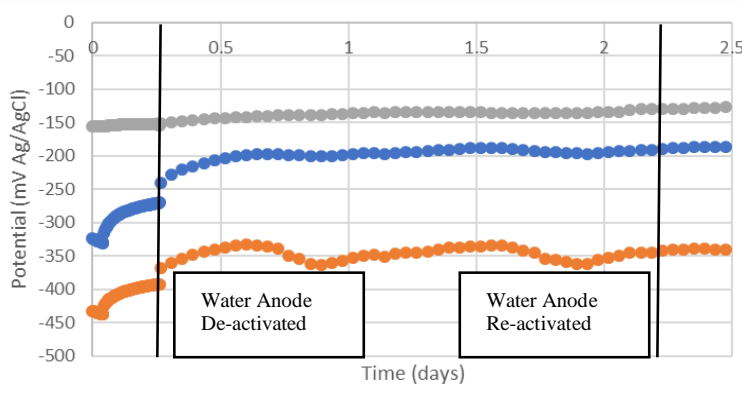

• Ref. $28 \bullet$ Ref. $29 \bullet$ Ref. 30

Fig. 6. Decay curves for reference electrode 28 (tidal, zone 6), reference electrode 29, (splash, zone 7) and reference electrode 30 (atmospheric, zone 8), Front Wall, Water Anode ReActivation Period

Table 1. Location and potential data for reference electrodes $(\mathrm{Ag} / \mathrm{AgCl})$

\begin{tabular}{|c|c|c|c|c|c|}
\hline Ref & Zone & Location & $\begin{array}{l}\text { On } \\
\text { potential }\end{array}$ & $\begin{array}{l}\text { Instant } \\
\text { Off } \\
\text { Potential }\end{array}$ & $\begin{array}{l}24 \text { Hour } \\
\text { Off } \\
\text { Potential }\end{array}$ \\
\hline 1 & 3 & T/FPC & -343 & -295 & -185 \\
\hline 2 & 4 & S/FPC & -456 & -319 & -176 \\
\hline 3 & 5 & $\mathrm{~A} / \mathrm{FPC}$ & -209 & -203 & -111 \\
\hline 4 & 6 & $\mathrm{~T} / \mathrm{FW}$ & -434 & -434 & -462 \\
\hline 5 & 7 & $\mathrm{~S} / \mathrm{FW}$ & -354 & -345 & -280 \\
\hline 6 & 8 & $\mathrm{~A} / \mathrm{FW}$ & -266 & -264 & -199 \\
\hline 7 & 3 & T/FPC & -464 & -425 & -331 \\
\hline 8 & 4 & S/FPC & -704 & -431 & -271 \\
\hline 9 & 5 & $\mathrm{~A} / \mathrm{FPC}$ & -302 & -295 & -201 \\
\hline 10 & 6 & $\mathrm{~T} / \mathrm{FW}$ & -689 & -677 & -641 \\
\hline 11 & 7 & S/FW & -505 & -460 & -378 \\
\hline 12 & 8 & $\mathrm{~A} / \mathrm{FW}$ & -465 & -447 & -238 \\
\hline 13 & 3 & T/FPC & -711 & -669 & -593 \\
\hline 14 & 4 & S/FPC & -681 & -563 & -383 \\
\hline 15 & 5 & $\mathrm{~A} / \mathrm{FPC}$ & -835 & -670 & -403 \\
\hline 16 & 6 & $\mathrm{~T} / \mathrm{FW}$ & -595 & -595 & -615 \\
\hline 17 & 7 & S/FW & -567 & -467 & -280 \\
\hline 18 & 8 & $\mathrm{~A} / \mathrm{FW}$ & -822 & -794 & -681 \\
\hline 19 & 3 & T/FPC & -210 & -210 & -205 \\
\hline 20 & 4 & S/FPC & -480 & -476 & -422 \\
\hline 21 & 5 & $\mathrm{~A} / \mathrm{FPC}$ & -414 & -397 & -268 \\
\hline 22 & 6 & $\mathrm{~T} / \mathrm{FW}$ & -730 & -707 & -490 \\
\hline 23 & 7 & S/FW & -375 & -358 & -168 \\
\hline 24 & 8 & $\mathrm{~A} / \mathrm{FW}$ & -146 & -148 & -145 \\
\hline 25 & 3 & T/FPC & N/A & N/A & N/A \\
\hline 26 & 4 & S/FPC & -774 & -691 & -521 \\
\hline
\end{tabular}

\begin{tabular}{|l|l|l|l|l|l|}
\hline Ref & Zone & Location & $\begin{array}{l}\text { On } \\
\text { potential }\end{array}$ & $\begin{array}{l}\text { Instant } \\
\text { Off } \\
\text { Potential }\end{array}$ & $\begin{array}{l}24 \text { Hour } \\
\text { Off } \\
\text { Potential }\end{array}$ \\
\hline 27 & 5 & A/FPC & -430 & -379 & -239 \\
\hline 28 & 6 & T/FW & -331 & -316 & -196 \\
\hline 29 & 7 & S/FW & -438 & -425 & -350 \\
\hline 30 & 8 & A/FW & -156 & -156 & -136 \\
\hline 31 & 3 & T/FPC & -611 & -389 & -163 \\
\hline 32 & 4 & S/FPC & -514 & -399 & -293 \\
\hline 33 & 5 & A/FPC & -431 & -372 & -214 \\
\hline 34 & 6 & T/FW & -499 & -478 & -386 \\
\hline 35 & 7 & S/FW & -360 & -356 & -302 \\
\hline 36 & 8 & A/FW & -317 & -322 & -272 \\
\hline 37 & 3 & T/FPC & -361 & -354 & -341 \\
\hline 38 & 4 & S/FPC & -427 & -381 & -320 \\
\hline 39 & 5 & A/FPC & -316 & -302 & -206 \\
\hline 40 & 6 & T/FW & -615 & -613 & -595 \\
\hline 41 & 7 & S/FW & -302 & -292 & -236 \\
\hline 42 & 8 & A/FW & -144 & -144 & -115 \\
\hline
\end{tabular}

\begin{tabular}{|c|c|c|c|c|c|}
\hline Ref & Zone & Location & $\begin{array}{l}24 \text { Hour } \\
\text { Decay }\end{array}$ & $\begin{array}{l}\text { Final } \\
\text { Off } \\
\text { Potential }\end{array}$ & $\begin{array}{l}\text { Final } \\
\text { Potential } \\
\text { Shift }\end{array}$ \\
\hline 1 & 3 & $\mathrm{~T} / \mathrm{FPC}$ & 110 & -145 & 150 \\
\hline 2 & 4 & S/FPC & 143 & -121 & 198 \\
\hline 3 & 5 & $\mathrm{~A} / \mathrm{FPC}$ & 92 & -79 & 124 \\
\hline 4 & 6 & $\mathrm{~T} / \mathrm{FW}$ & -28 & -430 & 4 \\
\hline 5 & 7 & S/FW & 65 & -262 & 83 \\
\hline 6 & 8 & $\mathrm{~A} / \mathrm{FW}$ & 65 & $\begin{array}{l}-173 \\
\end{array}$ & 91 \\
\hline 7 & 3 & $\mathrm{~T} / \mathrm{FPC}$ & 94 & -221 & 204 \\
\hline 8 & 4 & S/FPC & 160 & -73 & 358 \\
\hline 9 & 5 & $\mathrm{~A} / \mathrm{FPC}$ & 94 & -166 & 129 \\
\hline 10 & 6 & $\mathrm{~T} / \mathrm{FW}$ & 36 & -597 & 80 \\
\hline 11 & 7 & $\mathrm{~S} / \mathrm{FW}$ & 82 & -340 & 120 \\
\hline 12 & 8 & $\mathrm{~A} / \mathrm{FW}$ & 209 & -97 & 350 \\
\hline 13 & 3 & T/FPC & 76 & -415 & 254 \\
\hline 14 & 4 & S/FPC & 180 & -295 & 268 \\
\hline 15 & 5 & $\mathrm{~A} / \mathrm{FPC}$ & 267 & -256 & 414 \\
\hline 16 & 6 & $\mathrm{~T} / \mathrm{FW}$ & -20 & -539 & 56 \\
\hline 17 & 7 & S/FW & 187 & -258 & 209 \\
\hline 18 & 8 & $\mathrm{~A} / \mathrm{FW}$ & 113 & -348 & 446 \\
\hline 19 & 3 & $\mathrm{~T} / \mathrm{FPC}$ & 5 & -192 & 18 \\
\hline 20 & 4 & S/FPC & 54 & -279 & 197 \\
\hline 21 & 5 & $\mathrm{~A} / \mathrm{FPC}$ & 129 & -211 & 186 \\
\hline 22 & 6 & $\mathrm{~T} / \mathrm{FW}$ & 217 & -221 & 486 \\
\hline 23 & 7 & S/FW & 190 & -62 & 296 \\
\hline 24 & 8 & $\mathrm{~A} / \mathrm{FW}$ & 3 & -127 & 21 \\
\hline 25 & 3 & $\mathrm{~T} / \mathrm{FPC}$ & N/A & N/A & N/A \\
\hline 26 & 4 & S/FPC & 170 & -238 & 453 \\
\hline 27 & 5 & $\mathrm{~A} / \mathrm{FPC}$ & 140 & -207 & 172 \\
\hline 28 & 6 & $\mathrm{~T} / \mathrm{FW}$ & 120 & -192 & 124 \\
\hline 29 & 7 & $\mathrm{~S} / \mathrm{FW}$ & 75 & -323 & 102 \\
\hline 30 & 8 & $\mathrm{~A} / \mathrm{FW}$ & 20 & -112 & 44 \\
\hline 31 & 3 & $\mathrm{~T} / \mathrm{FPC}$ & 226 & -342 & 47 \\
\hline 32 & 4 & S/FPC & 106 & -245 & 154 \\
\hline 33 & 5 & $\mathrm{~A} / \mathrm{FPC}$ & 158 & -214 & 158 \\
\hline 34 & 6 & $\mathrm{~T} / \mathrm{FW}$ & 92 & -363 & 115 \\
\hline 35 & 7 & $\mathrm{~S} / \mathrm{FW}$ & 54 & -143 & 213 \\
\hline 36 & 8 & $\mathrm{~A} / \mathrm{FW}$ & 50 & -263 & 59 \\
\hline 37 & 3 & $\mathrm{~T} / \mathrm{FPC}$ & 13 & -302 & 52 \\
\hline 38 & 4 & S/FPC & 61 & -282 & 99 \\
\hline 39 & 5 & $\mathrm{~A} / \mathrm{FPC}$ & 96 & $\begin{array}{l}-189 \\
\end{array}$ & 113 \\
\hline 40 & 6 & $\mathrm{~T} / \mathrm{FW}$ & 18 & -478 & 135 \\
\hline 41 & 7 & S/FW & 56 & -205 & 87 \\
\hline 42 & 8 & $\mathrm{~A} / \mathrm{FW}$ & 29 & -102 & 42 \\
\hline
\end{tabular}

T- Tidal, S- Splash, A - Atmospheric, FPC - Front Pile Cap, FW - Front Wall 


\subsection{Discussion}

An analysis of the decay potentials after current switchoff reveals that 17 out of the 41 reference electrodes satisfy the decay criterion having a potential decay over a maximum of 24 hours of at least $100 \mathrm{mV}$ from the instantaneous off potential, with a further 5 almost achieving this with a decay of greater than $90 \mathrm{mV}$. There is no clear pattern in location of the reference electrodes achieving the $100 \mathrm{mV}$ decay criterion. There are two each in the tidal, splash and atmospheric zone for the front wall, and two in the tidal zone, five in the splash zone and four in the atmospheric zone for the front pile caps. These correspond to two in zones 3, 6, 7 and 8, three in zone 5 and four in zone 4 . However, considering those with a decay of greater than $90 \mathrm{mV}$ this increases those in the atmospheric zone of the front pile cap to six, which may indicate that protection is being achieved more readily in the front pile caps than in the front wall. Furthermore, three of the five reference electrodes are located in zone 5 , bringing the total located in zones 4 and 5 to 10 out of 22 . A possible explanation is that this is the central section of Berth 6, which is protected whenever a ship is moored at the berth, irrespective of the ship length. This could translate into a more sheltered environment within these zones which is less aggressive with respect to being susceptible to tidal action and chloride deposition, which translates to less aggressive environment with regards to corrosion of the reinforcing steel.

Based on the 24-hour criterion, two locations actually demonstrate a negative decay, Ref. 4 and Ref. 16, both in the tidal zone of the front wall in zone 6 . This indicates that protection is not being achieved in this location. When considering the extended potential decay, 72 hours, there is no change in the number of reference electrodes achieving the protection criteria, with Ref. 4 and Ref. 16 both still displaying negative decays.

Only one achieves a more negative instant off potential than $-720 \mathrm{mV}$, Ref. 18 , in the atmospheric zone of the front wall in zone 8. However, 10 reference electrodes achieve the absolute criterion of $-150 \mathrm{mV}$. These include six reference electrodes that did not achieve any of the other three criteria. Five of these are in the atmospheric zone and one in the splash zone. This can be attributed to the local environment. Those electrodes in the atmospheric zone are influenced less by the tidal pattern, as observed in Figs 3-5 and have more positive potentials. Thus, they are more likely to achieve the absolute passive criterion but given their more positive instant off potentials, they are less likely to achieve the $100 \mathrm{mV}$ decay criterion.

The decay curves also clearly show the impact of the de-activation of the water anode, Figure 6 . At the point of de-activation there is a distinct positive shift in the reference electrode potentials, generally of the order of $10-25 \mathrm{mV}$. This shift is evident in the tidal and splash zones for most reference electrodes, as would be expected as these are in direct contact with the water. In most instances a smaller increase is observed in the atmospheric zone. Shifts of up to around $50 \mathrm{mV}$ are observed in some cases, e.g. Ref 37, Figure 5. The larger shifts observed are associated with those reference electrodes displaying a more negative instant off potential. It is hypothesised that this is due to the exact location of these electrodes. While the tidal, splash and atmospheric zones are designated in the reports, the actual location is not provided and it may be that these electrodes are in direct contact with the sea water, even though they are nominally in the atmospheric zone. The positive shifts observed are attributed to the cessation of the cathodic protection afforded by the water anodes, in effect being an "instant off" for the water anodes.

Given the point in time at 0.25 days from the deactivation of the ICCP system, this shift is a contributing factor in the 24 hour and 72-hour decay values. If this was subtracted from the 24-hour decay values, a further 4 reference electrodes would not achieve the $100 \mathrm{mv}$ criterion. It is interesting to note that the re-activation of the water anodes after a 48 hour off period has no discernible effect on the decay pattern for any of the electrodes, whatever the location. As such there is no evidence that the water anodes are providing any contribution to the "residual" protection to the steel when they are operating and the ICCP system is deactivated. If the initial positive shift from the deactivation of the water anodes is subtracted from the final potential measured, only an additional 3 electrodes would have values more negative than the instant off potentials.

The shape of the potential decay versus time plot can also be used to provide an indication of the corrosion activity occurring on the reinforcing steel following deactivation of the ICCP system [17]. Re-activation of corrosion in the steel is characterised by a potential shift to more negative values. A strong indicator of activation in this manner is a return to the steel native values (pre ICCP value). This re-activation behaviour can be distinguished from negative excursions caused by the tidal variations as being a sustained negative trend in the steel potentials independent of the tidal action from which the steel potential recovers to its original or more positive values at the end of the tidal cycle. It is interesting to note that 39 out of the 41 operational reference electrodes give a more positive potential value at the conclusion of the 84 day trial than their instant off value, including Ref 4 \& 6 which gave a negative shift at 24 and 72 hours. One electrode, Ref. 33, in zone 5 in the atmospheric zone of a front pile cap has an identical value to that recorded after 24 hours after the instant off, and Ref. 31, in zone 3 in the tidal zone is the only reference electrode to display a final potential more negative than the 24 hour decay value, though this is still more positive than the instant off potential by $47 \mathrm{mV}$. All electrodes moved to a more positive potential following the de-activation of the ICCP system compared to their instant off value at some point in the 84 days. If this decay trend is used as an indication of passivity of the reinforcing steel, then this would indicate that residual protection is being afforded to the steel at all locations at least for a period following deactivation of the ICCP system.

An analysis of the decay over the trial period identifies only two electrodes that display a sharp fall in 
potential, suggesting re-initiation of corrosion Figure 7 [14]. These are Ref. 19 (71 days) and Ref. 31 (15 days), both of which are located in the tidal zone of the front wall cap in zone 3 . However, a further 15 show a slight downward trend in the last 15-20 days of the trial, though this may be an effect of the tidal variations. Thus 22 show no evidence of re-activation at any point during the trial. With all the reference electrodes in the atmospheric zone indicating that protection has been maintained for the full 84 day period.

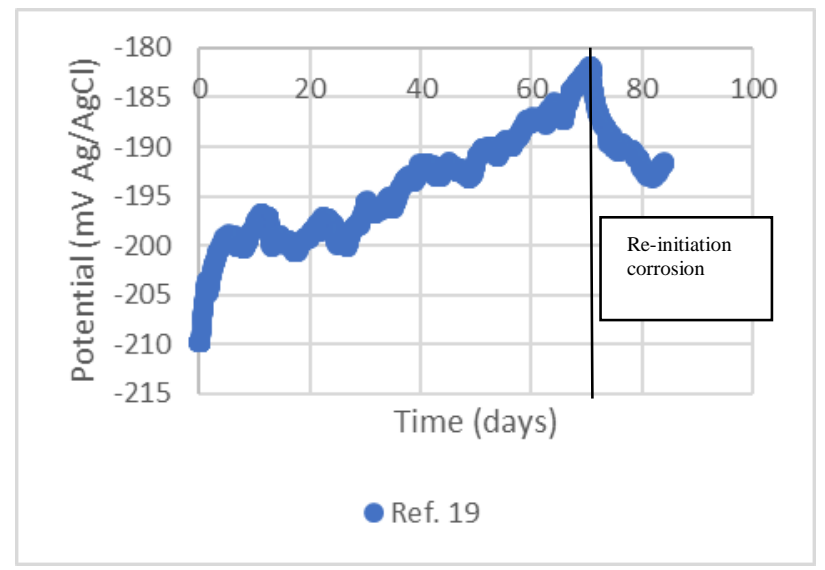

Fig. 7. Decay curves for reference electrode 19 (tidal, zone 3),

In order to further understand the behaviour of the residual protection observed, additional data is being sought with regard to the protection current applied over the lifetime of the ICCP system. At present, data has only been obtained for the period 2007-2009. The anode currents were reported to vary between a maximum of 26.5 Amps and a minimum of 16.0 Amps across all zones both rear and front with a mean current of 20.4 Amps recorded, with a total current of 367 Amps. For the front zones the maximum was 26.5 Amps and the minimum was 18.5 Amps, with a mean current of 23.6 Amps. Additional data covering the full operational life and the steel quantities, to determine the current densities is required to enable a greater knowledge of factors affecting the level of residual protection that can be achieved on structures protected by ICCP systems. The system was designed with a maximum current density of $20 \mathrm{~mA} / \mathrm{m}^{2}$ of steel renforcement surface area. While the steel area is not known for Berth 6 based on other berths at Portland it is estimated that the current density is likely to be between 0.5 and $2.5 \mathrm{~mA} / \mathrm{m}^{2}$ [14] However, the results do show that residual protection can be achieved when ICCP systems are de-activated.

\section{CONCLUSIONS}

Based upon the potential data from the de-activation of the ICCP system at Berth 6 at Portland the following conclusions were noted;

1. A total of 17 of the 41 reference electrodes achieved a $100 \mathrm{mv}$ decay in 24 hours, satisfying the decay criterion for protection. A further 5 had a potential decay of greater than $90 \mathrm{mV}$.

2. Only one achieved a more negative instant off potential than $-720 \mathrm{mV}$.

3. A total 10 reference electrodes achieved the absolute criterion of $-150 \mathrm{mV}$. These include six reference electrodes that did not achieve any of the other criteria. This is attributed to their location where lack of moisture resulted in an instant off potential from which it was not possible to achieve a $100 \mathrm{mV}$ decay.

4. The de-activation of the water anode resulted in a positive shift of up to $50 \mathrm{mV}$ depending upon the location of the reference electrode.

5. The re-activation of the water anode had no discernible effect on the electrode potential.

6. A total of 39 out of the 41 operational reference electrodes gave a more positive potential value at the conclusion of the 84-day trial than their instant off value.

7. Based upon the shape of the potential decay curves over the 84-day trial, residual protection was afforded to all the locations for at least some period during the trial.

8. Only two electrodes display a sharp fall in potential, characteristic of the re-initiation of corrosion, while 22 show no evidence of the re-initiation of corrosion over the trial based on the shape of the decay curve.

\section{ACKNOWLEDGEMENTS}

The authors wish to acknowledge the assistance of the Port of Portland, Eldridge Electrical and Bruce Ackland in the undertaking of the ICCP trial at the Port of Portland.

\section{REFERENCES}

1. Bertolini, L., et al., Corrosion of Steel in Concrete: Prevention, Diagnosis, Repair, 2nd Edition. 2013: Wiley \& Sons.

2. Chaussadent, T. and R. Dron, Influence of hydroxyls, carbonates and chloride ions on the pitting corrosion of steel. Materiales de construcción, 1992. 42(226): p. 49-62.

3. Glass, G. and N.R. Buenfeld, Chloride-induced corrosion of steel in concrete,. Progress in Structural Engineering \& Materials, 2000: p. 448458.

4. Angst, U., et al., Critical chloride content in reinforced concrete - A review. Cement and Concrete Research, 2009. 39(12): p. 1122-1138.

5. Robery, P., M. Gower, and S. El-Belbol, Comparison between cathodic protection and other electrochemical repair techniques, in 7th international conference on structural faults and repair concrete and composites,. 1997. p. 231237.

6. Glass, G.K. and N.R. Buenfeld, On the CurrentDensity Required to Protect Steel in 
Atmospherically Exposed Concrete Structures. Corrosion Science, 1995. 37(10): p. 1643-1646.

7. Jones, D.A., Application of Electrode Kinetics to Theory and Practice of Cathodic Protection. Corrosion Science, 1971. 11(6): p. 439-\&.

8. Page, C.L. and G. Sergi, Developments in cathodic protection applied to reinforced concrete. Journal of Materials in Civil Engineering, 2000. 12(1): p. 8-15.

9. Glass, G.K. and J.R. Chadwick, An Investigation into the Mechanisms of Protection Afforded by a Cathodic Current and the Implications for Advances in the Field of Cathodic Protection. Corrosion Science, 1994. 36(12): p. 2193-2209.

10. Glass, G.K., W.K. Green, and J.R. Chadwick, Long term performance of cathodic protection systems on reinforced concrete structures, in $U K$ Corrosion 91. 1991: Manchester;UK.

11. Presuel-Moreno, F., A.A. Sagues, and S.C. Kranc, Steel activation in concrete following interruption of long-term cathodic polarization. Corrosion, 2005. 61(5): p. 428-436.

12. Broomfield, J.P. and J.S. Tinnea, Cathodic protection of reinforced concrete bridge components, in Report ID No: SHRPCUWP92618,. 1992.

13. Christodoulou, C., et al., Assessing the long term benefits of Impressed Current Cathodic Protection. Corrosion Science, 2010. 52(8): p. 2671-2679.

14. Law, D.W., P. Nicholls, and C. Christodoulou, Residual protection of steel following suspension of Impressed Current Cathodic Protection system on a wharf structure. Construction and Building Materials, 2019. 210: p. 48-55.

15. AS2832.5, AS 2328.5 Cathodic Protection of Metals; Part 5 Steel in Concrete, in 2008, Australian Standards.

16. ISO:12696:2016, Cathodic protection of steel in concrete. 2016.

17. Bhuiyan, M.A., et al., Investigation of Residual Protection of Steel following Application of Protective Current. Construction and Building Materials, 2018. 162: p. 503-511. 